\title{
Revolution and Challenge - A New Scrutiny of Digital Media Art Education Scene Under 5G Field
}

\author{
Yingquan Wang ${ }^{1, *}$ \\ ${ }^{1}$ Department of Digital Media Arts, Qingdao Huanghai College, Qingdao, Shandong Province, China \\ *Corresponding author. Email: 653934872@qq.com
}

\begin{abstract}
The intelligent development of education has become an essential direction of education and teaching reform, and the popularization and application of 5G technology provides strong support for the technical development of education. The integration of $5 \mathrm{G}$ and education will trigger the revolution of scene elements such as teachers, students, learning environment and learning resources.This essay puts forward some constructive suggestions and thoughts by analyzing the elements of educational scenes under the 5G vision. Taking the digital media art major as an example, this essay illustrates the revolution and challenges of the elements of educational scenes under the $5 \mathrm{G}$ vision, with the aim of promoting the process of educational reform and educational informationization, thus smoothly promoting the realization of educational informationization 2.0.
\end{abstract}

Keywords: 5G, Digital media art, Educational scenes, Elements

\section{INTRODUCTION}

With the continuous innovation and changes of technology under the information age, the ways of informational teaching in the field of education are gradually popularized. With the appearance of innovative course teaching, flipped classroom, interdisciplinary and smart classroom, the paths for our students to acquire knowledge and teachers to impart knowledge have undergone essential changes.At present, in the information age, the learning contents and knowledge itself have the features of diversity, freedom and entertainment.

After the industrial era and $\mathrm{PC}$ (personal computer) Internet era, human beings have entered the mobile Internet era represented by smart phones, and various educational and learning activities in the field of education based on the Internet have gradually become popular and become the mainstream.However,there are some constraints in Internet technology and network speed.Due to them, it caused some negative impacts. On the one hand, in the current teaching scene environment, many teaching resources are static text information and image elements, while various audio and video animation elements that have emerged in recent years need to depend on the wireless Wifi environment, so that students can use and learn[1]. When they study without Wifi, they need a lot of data traffic to provide support, and sometimes they have to abandon the corresponding learning resources; in addition, the different needs of different students can not be met correspondingly, and the learning effect is not so good.On the other hand, as a typical interdisciplinary major, digital media art embodies the concepts of science, art and humanity. With the new technology--image transmission and processing needs higher speed network to communicate, but at present the low bandwidth and high delay of $4 \mathrm{G}$ network obviously restrain its development.

The realization of $5 \mathrm{G}$ technology has changed the inherent way of life, work and learning of human beings. What is more powerful is that it has realized the interconnection of everything and intelligent interconnection.Author thought,the integration of $5 \mathrm{G}$ with new technologies such as big data, artificial Intelligence and cloud computing is bound to lead to reforms in the education scene.Students, teachers, resources, learning scenes and other elements will undergo profound changes, At the same time, it has great influence on the traditional educational idea and teaching method(see figure1).All in all,The promotion and application of $5 \mathrm{G}$ technology will vigorously enrich the dimensions of the education scene, meet the individual needs of art education, especially digital media art education, and promote the process of education reform and informatization.

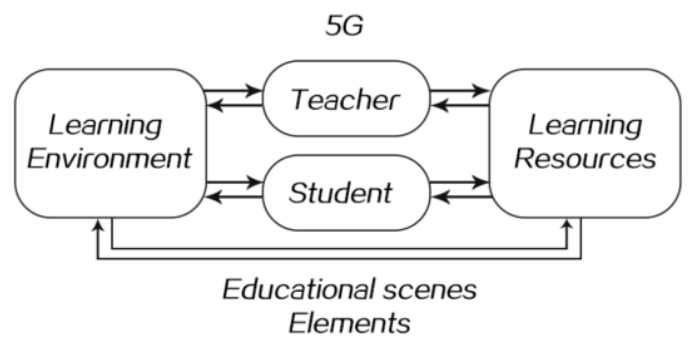

Figure 1 Education scene under $5 \mathrm{G}$ field 


\section{STUDENT ELEMENTS: LEARNING AUTONOMY AND DIVERSITY}

\subsection{The autonomy of learning can be improved}

In the $4 \mathrm{G}$ era, with the successful development of online classes such as MOOC, students have already adapted and accepted the way of learning online and acquiring the knowledge online with convenience and diversity. Furthermore, the rapid development of mobile media era endows students with innate applicability in using and accepting new technologies. With the advent of $5 \mathrm{G}$ era, learning methods will become more convenient and efficient by taking advantage of many new features of technology[2]. For the ontology of students, psychological features such as freshness and curiosity determine that learning autonomy will inevitably be improved greatly. In addition, the continuous maturity of AR, VR, MR and other technologies creates a rich and varied teaching environment, which makes it easier for students to have an immersive learning atmosphere, which can undoubtedly stimulate the potential learning motivation and interest.So students are essentially very willing to try new things and expand themselves. Therefore, under the influence of $5 \mathrm{G}$ technology, it can not only improve students' autonomy in learning, but also train students' thinking and methods of exploring the problems.

\subsection{The choices of learning is more abundant}

At present, the teaching methods and resources in digital media art education students can choose is within limitation, which are only traditional offline classes, online courses or mixed courses between online and offline.And the teaching resources are also limited to the teaching resources developed in their schools and a small amount of resources on the Internet.In the $5 \mathrm{G}$ era, students have greatly improvement on their selectivity.In terms of learning fields and resources, students can choose virtual reality technology, augmented reality technology, interactive touch technology, aircraft and technology products and so on relying on new technologies with freedom.In particular, the mature development of $5 \mathrm{G}+\mathrm{VUI}$ (Voice User Interface) provides more abundant applications in teaching scenes, and students can realize the multidimensional learning by relying on voice interaction interface technology. All these visions can be realized under $5 \mathrm{G}$ super-stable and low latency technology.

\subsection{The ability of practice is improved}

In order to become the focus of teaching reform, the cultivation of practical ability of current students can be examined through professional practice teaching, innovation and entrepreneurship cultivation and professional practice training.In the $5 \mathrm{G}$ era,Will continue to improve the above project content,and make corresponding combination with big data + AI artificial intelligence.In the future vision,Students majoring in digital media art can set up virtual practice scenes in aspects such as internship and training. Students can combine their own abilities and current employment needs to develop appropriate practice plans.In addition,With the influence of $5 \mathrm{G}$ technology on all walks of life, students can form the comprehensive ability of independent thinking and independent operation with the help of $5 \mathrm{G}$ characteristics.

\section{TEACHER ELEMENTS: FLEXIBLE AND CHANGEABLE TEACHING}

\subsection{The upgrading of the status of teachers}

The Influence of 5G Technology in the future teaching, the teachers' teaching ability and technical ability will face some new challenges. At the same time, they can not only take advantage of the convenience and speed of intelligent technology, but also improve their own abilities continuously, especially the progress in their professional fields. For the teaching of digital media art major, under the circumstances of constant changes in emerging technologies, teachers should accurately locate the learning contents and teaching methods of different professional courses and form teaching contents with differentiation.With the help of 5G, AI (Artificial Intelligence ), big data and other technologies, the identity of ordinary teachers has been upgraded to super teachers, and new technologies will push forward teaching and support teaching. At the same time, facing the teaching work of digital media art major, teachers also should cooperate with intelligent robots to provide another new teaching thinking mode for students.

\subsection{The promotion of behavior of teachers}

With the development of Internet technology, huge changes have taken place in people's cognition and knowledge acquisition. In the $5 \mathrm{G}$ era, similarly, same students no longer rely on a single teaching method or traditional textbooks to acquire knowledge. There are massive knowledge and skills existing in the Internet. Correspondingly, for the change of teachers' teaching behavior, teachers need to develop new teaching methods, from the traditional single acquisition of knowledge to the level of $5 \mathrm{G}$ cloud storage knowledge sharing. In addition, for the changes of teaching behavior, teachers should pay more attention to the change of teaching habits and teaching scenes, so that the teaching methods and teaching behaviors in the $5 \mathrm{G}$ era can be filled with diversity and content[3].Also, for digital media art professional teachers, more needs to be corresponding professional core courses do related changes, such as the cross-media integrated 
design of the virtual reality technology, the video special design "course such as $5 \mathrm{G}$ must make good use of the Internet character such as high data rate, less delay, for multiple teaching scene and innovative teaching methods to do research.

\subsection{The revolution of educational idea}

Teachers' educational concept is defined as "understanding of educational process issues, such as educational objective view, educational practice view, educational object view and educational curriculum view".This concept is promoted to the educational and teaching concept in $5 \mathrm{G}$ era. It is necessary to adapt to and make good use of the high data rate and mass storage scale characteristics of 5G technology, and develop novel teaching interaction methods and concepts.Teachers should replace the old with the new regardless of the innovation of traditional teaching and learning concepts. The change of teaching philosophy is not achieved overnight. It should be a process and a normal state. Under the guidance of national policies and the effective support of technology, it should be carried out and improved gradually.

\section{THE ELEMENTS OF LEARNING ENVIRONMENT: ABUNDANCE AND FREEDOM}

\subsection{The application of simulation laboratory}

In recent years, the Ministry of Education and provincial and municipal educational institutions have carried out the construction of simulation experiment teaching projects on after another, involving the classification of biological sciences, energy and power, civil engineering, aerospace, art design and pedagogy[4]. With the continuous construction and application of simulation laboratory, there are indepth researches on teaching contents, teaching methods, teaching effects, teaching resources and shared services.As for digital media major, VR virtual reality laboratory, AR augmented laboratory and MR mixed reality laboratory are gradually built up, and the exploration of future teaching mode is gradually being carried out. However,due to the limitation of $4 \mathrm{G}$ communication technology,now it can not meet the specific use requirements of various simulation laboratories. Therefore, if we want the simulation laboratory to be really put into normal teaching, it must rely on the characteristics of $5 \mathrm{G}$ millisecond delay time and user experience data rate.

In the $5 \mathrm{G}$ era, it can not only solve the problem of speeding up the performance of network, but also can provide effective packaging for big data transmission and computing. Courses such as VR virtual reality application and AR augmented technology practice in digital media art major can be controlled by multiple devices in the simulation laboratory, and real time sharing and real time feedback can be made use of Internet technology, which will greatly improve the efficiency of learning and practice in the future. The mixed practical application of $5 \mathrm{G}+\mathrm{VR}+\mathrm{AR}+\mathrm{MR}$ mode can synchronously combine and transform the real experimental environment with the online virtual environment, realize the visual operation of the virtual scene, and then build a bridge between reality and virtual space to provide teachers and students with a dynamic and real time interactive teaching and learning environment.In addition, the application of various simulation laboratories can effectively improve the conversion rate of knowledge. Instead of boring and obscure knowledge, students will face with vivid and real objects that can be contacted in close, which fundamentally solve the problem of ontology differences and improve the efficiency of acquiring knowledge and practicing knowledge.

It can be seen that $5 \mathrm{G}$ technology provides a strong guarantee for the application of simulation laboratory, and as for the development of teaching scenes for digital media art ,it also provides sufficient space. The $5 \mathrm{G}+$ simulation laboratory will become a new situation of spreading knowledge,it can effectively change the way students acquire knowledge and thus form an active acceptance mode. Teachers and students will have thinking paths to solve and explore the problems.

\subsection{The upgrading of online learning mode}

The national online learning platform for excellent courses has launched nearly a hundred excellent courses for digital media art majors, which are online courses with high quality. The learning tasks of students are no longer limited to schools, and they can learn anytime, anywhere.At the beginning of 2020, during the outbreak and spread of COVID-19, classes were suspended, and many colleges and universities used online excellent courses to complete their planned teaching content. Teachers used both online network teaching methods and online platform courses to complete all aspects of teaching plans with students from different places.Therefore, in view of the development in recent years, the online learning mode is about to replace traditional teaching mode, because online learning mode has many advantages that traditional teaching mode can not compare with, whether it is online courses or online and offline mixed courses, and it can provide dynamic, modular and systematic teaching environment and teaching resources for learners in all aspects.

How to optimize the existing high-quality online course resources is a new topic proposed in the $5 \mathrm{G}$ era.Through the combination of 5G technology and online learning mode, we expect to provide learners with a more intuitive, effective and convenient learning environment and provide learners with a method to specifically describe students' behavioral patterns and potential cognitive processes.Under the support of 5G technology, the online 
learning mode has a more three-dimensional effect[5]. It can get rid of static or two-dimensional learning scenes and disseminate content information in multiple ways, such as text, audio, video and animation, so as to attract students' attention and improve their visual understanding and application of knowledge.

There are many courses that can be applied in digital media art major, such as Audio and Visual Language of Film and Television, Digital Image Processing, Video Special Effects and Nonlinear Editing, Animation Principle and Online Game Design, Virtual Reality, Experimental Image and so on. The shortcomings that incomplete coverage, network rate delay and high traffic charges in current $4 \mathrm{G}$ communication are improved by $5 \mathrm{G}$ technology.Under the supported by the key characteristics of 5G technology, the super Internet will be mature, and online learning resources and course contents such as MOOC will be smoother in terms of user experience, forming a new online course teaching mode of $5 \mathrm{G}+\mathrm{MOOC}$ to achieve learning effects of online education with high quality, high efficiency and high frequency.

\subsection{The customization of personalized learning environment}

With the rapid development of network technology, students' learning environment needs are constantly improving, and their learning methods are also changing. Emerging customized learning content and personalized learning methods have become the first choice.By presenting personalized learning needs, students can meet their own needs and characteristics, and have autonomy and control over their own learning process, so that learning becomes an internal way of behavior.

In many courses of digital media art major, we can establish personalized learning environment. For example, as for visual design courses, we can use brain wave tracking or eye tracker, etc in order to track and judge the law of change of visual effects in students' learning process in real time, and to control their learning progress or learning quality.In this essay, the author discusses that the customization of personalized learning environment is based on the premise of respecting the individuals, so only by fully understanding and mastering the precise needs of learning individuals or ontology can the learning quality be improved on purpose. This customized learning environment can maximize the potential of students, and fundamentally change the way of thinking and practice of in learning, which is also an important content of personalized learning and customized learning in the $5 \mathrm{G}$ era.

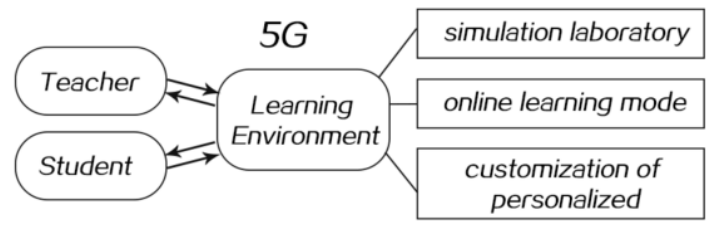

Figure 2 Learning environment elements interact

\section{CONCLUSION}

At present, the intelligentization of education has become a main stream of education and teaching reform, which has long been hindered by the unsatisfying network condition, especially by the inadequate wireless network coverage and limited $4 \mathrm{G}$ transmission rate. Because of this, the popularization and application of $5 \mathrm{G}$ technology provides a strong support for the intelligent and technical development of education.

This essay discusses the practical research of 5G technology on the educational scenes of digital media art major. On the one hand, we take the influence of $5 \mathrm{G}$ technology on education reform as the foothold, it provides the guidance for the reform and development of higher education under the new technology. On the other hand, for digital media art major, which is a new professional major, how to develop better and better is also a problem that educators have been exploring for a long time.This essay puts forward some constructive suggestions and thoughts by analyzing the elements of educational scenes under the $5 \mathrm{G}$ vision. Taking the digital media art major as an example, this essay illustrates the revolution and challenges of the elements of educational scenes under the $5 \mathrm{G}$ vision, with the aim of promoting the process of educational reform and educational informationization, thus smoothly promoting the realization of educational informationization 2.0.

\section{ACKNOWLEDGMENT}

This essay is concerned about the special project of art education in Shandong Province in 2019: The Practical Research of 5G Technology in Digital Media Art Education Scenes (YJ201911084).

\section{REFERENCES}

[1]] Gonzalez P A, Ashworth L, McKeen J. The CIO Stereotype: Content, Bias, and Impact [J]. The Journal of Strategic Information Systems, 2018,28(1):83-99.

[2] Yuan Lei, Zhang Yanli, Luo Gang. The Change of Elements of Educational Scene in 5G Era and the Strategies[J]. Journal of Distance

Education,2019(05):27-37.

[3] Chun M, Mooney J. CIO Roles and Responsibilities: Twenty-five Years of Evolution and Change[J]. Information \& Management, 2009(6):323-334.

[4] Zheng M, Chu C-C, Wu Y, Gou W. The Mapping of On-Line Learning to Flipped Classroom: Small Private Online Course[J]. Sustainability,2018,10(3):748.

[5] Sun Chongyong, Li Shulian. Cognitive load theory and its application in teaching design [M]. Tsinghua University 